\title{
DEVELOPMENT OF A MULTI-FUNCTIONAL VENTILATED FAÇADE WITH AN INTEGRATED COLLECTOR-STORAGE: NUMERICAL MODEL AND EXPERIMENTAL FACILITY
}

\author{
Deniz Kizildag, Ivette Rodriguez and Assensi Oliva \\ Centre Tecnològic de Transferencia de Calor (CTTC) \\ Universitat Politècnica de Catalunya (UPC) \\ ETSEIAT, Colom 11, 08222 Terrassa (Barcelona), Spain \\ Fax: +34 937398920 e-mail: cttc@cttc.upc.edu
}

\begin{abstract}
The paper reports on physical modeling and experimental evaluation of glazed systems. A multi-functional ventilated façade with an integrated collector-storage is developed and mounted on a test cell facility under real weather conditions. The component uses solar radiation to produce solar heated water flow, which in turn can provide space heating or fulfill domestic hot water demands. Different operational modes of the ventilation channel are analyzed in order to improve the thermal performance of the buildings with glazed façades.

The existing numerical platform for the prediction of the thermal performance of buildings and solar systems is used to implement a numerical model to address the multi-functional ventilated façade with integrated collector-storage element. The model uses the measured outdoor data as boundary conditions to obtain predictions by means of a general energy balance in the test room and the façade component. The model permits different levels of simulation depending on the desired precision in each element, applying a modular methodology. In this study, the convection heat transfer coefficient within the parallelepiped storage tank is obtained from a direct numerical simulation (DNS) of turbulent natural convection flow of water, while the remaining empirical information is obtained from the literature for similar geometries.
\end{abstract}

\section{Introduction}

The existing buildings account for over $40 \%$ of the total energy consumption in Europe. Growth in population, increasing demand for building services and comfort levels, together with the rise in time spent inside the buildings, indicate that the upward trend in energy consumption within buildings will continue to grow (Pérez-Lombard et al., 2008). This fact not only stimulates the efforts in the development of innovative and efficient products of reduced environmental impact, but also makes necessary tools and methodologies for analyzing the performance of these products and the buildings into which they are integrated (Bloem et al., 2010).

The envelopes play an important role in the thermal behavior of the buildings. In addition to fulfilling the architectural requirements, the energy efficient design of the building envelopes can contribute greatly in reducing the heating and cooling loads of the dwellings (Faggembauu, 2006). Multi-functional ventilated façades appear as an interesting solution taking into consideration aspects like improved thermal behavior, acoustic insulation and daylight illumination, attractive outdoor aspect, possibility to incorporate innovative elements.

The present work is on physical modeling and experimental evaluation of glazed systems. An integrated collector-storage element composed of a single glass pane, a layer of transparent insulation material (TIM), a parallelepiped storage tank with selective absorber surface, and opaque insulation is developed. This element, as a whole, works as an opaque element that produces solar heated water. Two cases have been considered in this work:

- CASE A: The integrated collector-storage element is mounted on a south facing aperture of the controlled test room as a single skin opaque element. 
- $\quad$ CASE B: A double skin façade component is mounted where an external single-pane glass skin is separated from the inner skin by a ventilation channel. Natural and forced convection operational modes are possible. The inner skin consists of two zones: i) the upper double-pane glass skin, ii) the lower integrated collector-storage element.

The test facility is equipped with a data acquisition system monitoring outdoor and indoor climate conditions, namely the total and diffuse radiation incident on the façade, wind direction and velocity, air temperatures, relative humidity, and the temperatures at various test cell facility surfaces.

The numerical model to address the multi-functional ventilated façade with integrated collector-storage element (Faggembauu et al., 2003) is adapted to the existing numerical platform for the prediction of the thermal performance of buildings and solar systems (Damle et al., 2011). This object-oriented modular platform is intended to permit coupling between low level resolution models and CFD models based on large eddy simulation (LES) models or DNS, so that some critical zones within the façades or buildings can be modeled with more detail than others.

The collected experimental data is processed and analyzed to validate the numerical model, and to obtain a better understanding of the thermal behavior of the component.

Expected results are given for some operational modes, by comparing the numerically calculated and the measured test cell facility temperatures at different zones.

\section{Experimental Facility}

The scheme of the multi-functional ventilated façade is shown in Figure 1. The outer skin of the façade is composed of a single-pane glass layer. The inner skin is separated from the outer skin by means of an air channel. The air flow in the air channel can be due to natural or forced convection. The inner skin is composed of two zones. The upper zone is of double-pane glass, while in the lower zone the integrated collector-storage element is installed.

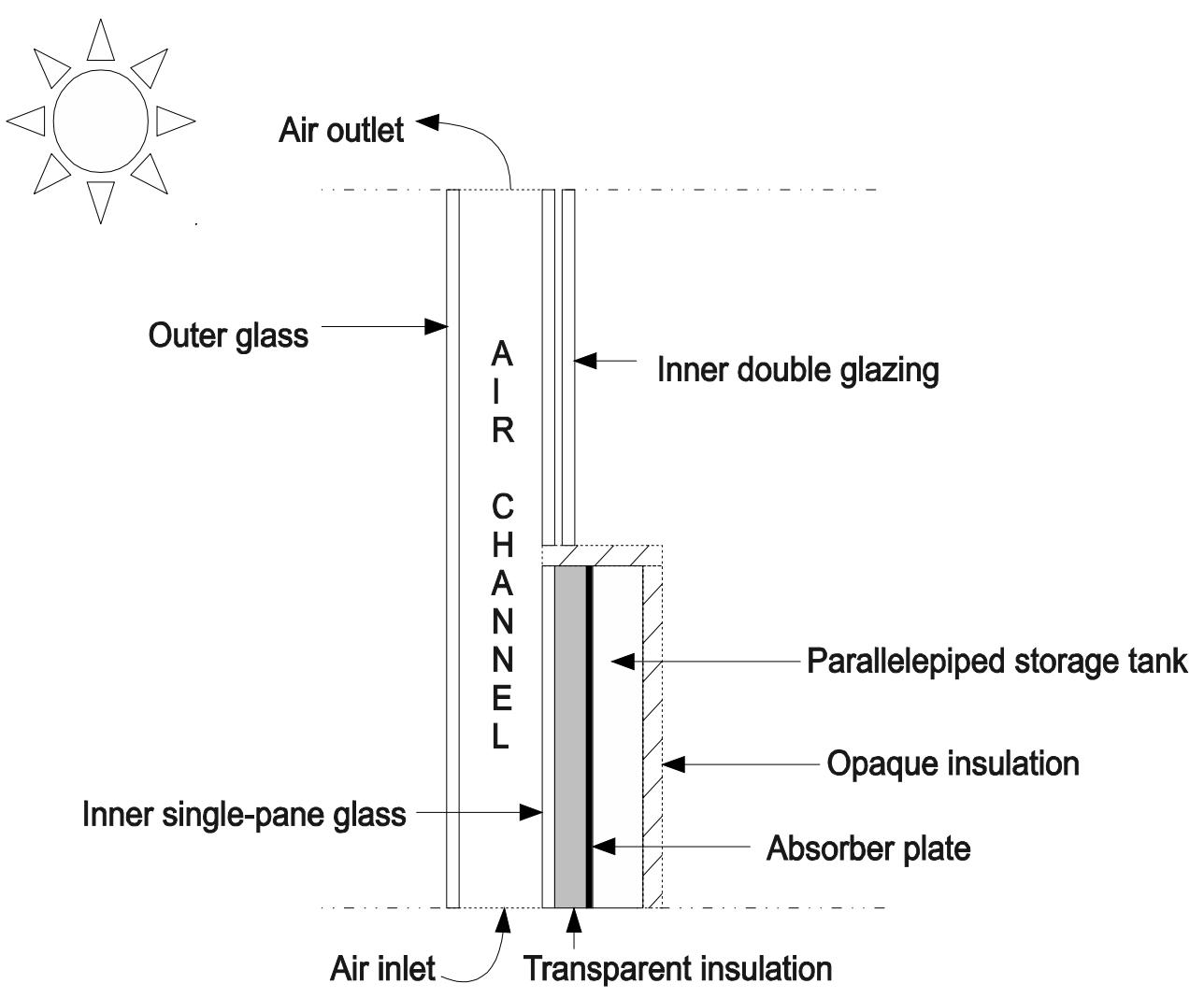

Fig. 1: Scheme of the multi-functional façade (CASE B) 


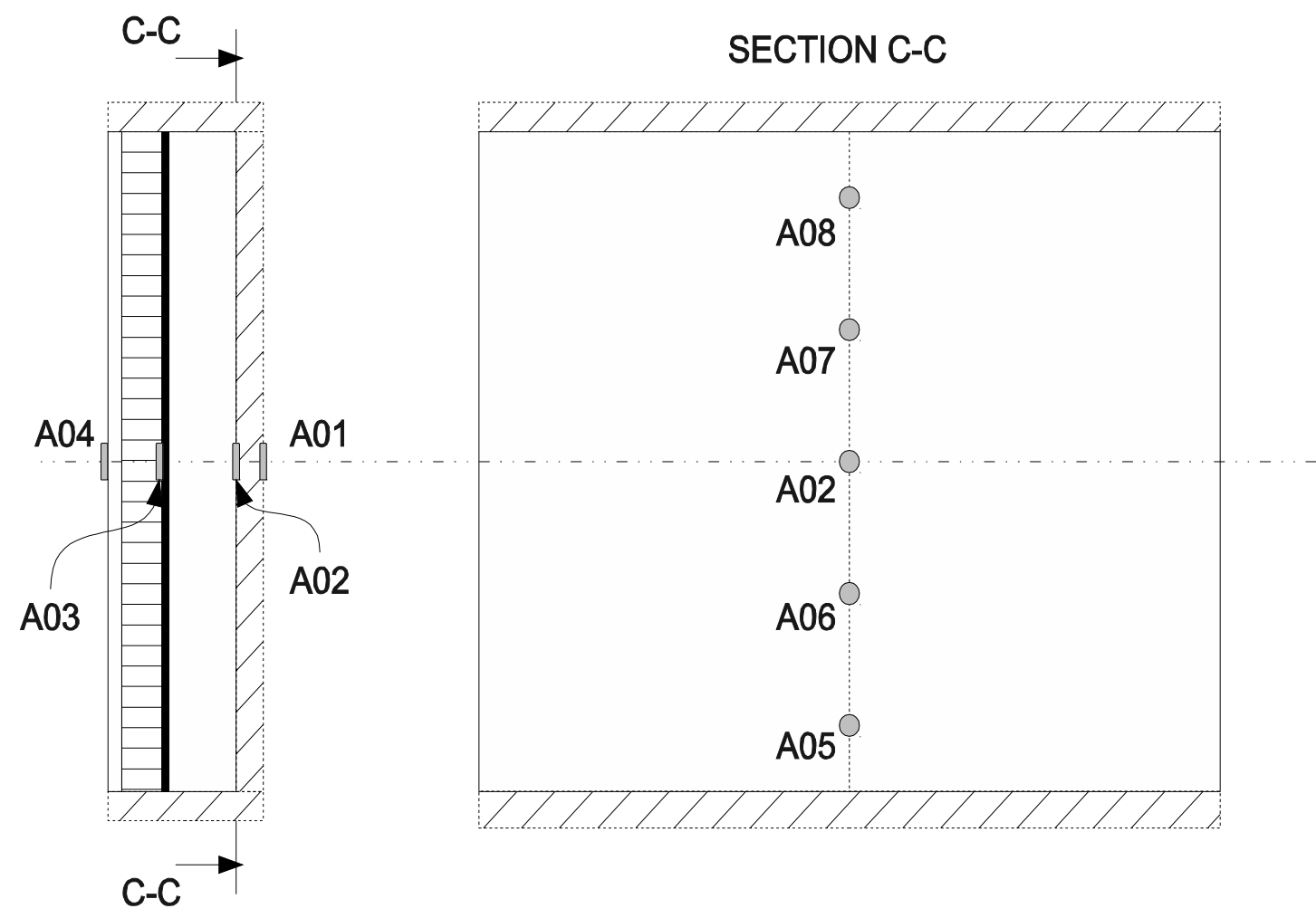

Fig. 2: Probe location in the integrated collector-storage element

The experimental facility is equipped with sensors to measure the temperatures in different façade zones and the meteorological data by means of a data acquisition system composed of a PC and a data acquisition unit. The metrological data registered during the experiment is: i) diffuse radiation on horizontal surface, ii) total radiation on horizontal surface, iii) outdoor ambient temperature, iv) wind velocity, v) wind direction, vi) relative humidity, vii) diffuse radiation on the façade surface, viii) total radiation on the façade surface, ix) indoor ambient temperature.

Regarding the integrated collector-storage element, temperatures at the indoor and outdoor wall surfaces, at the absorber plate, at both vertical confining walls of the parallelepiped storage tank, together with the temperatures within the storage element are registered. The locations of these thermocouple probes are shown in Figure 2.

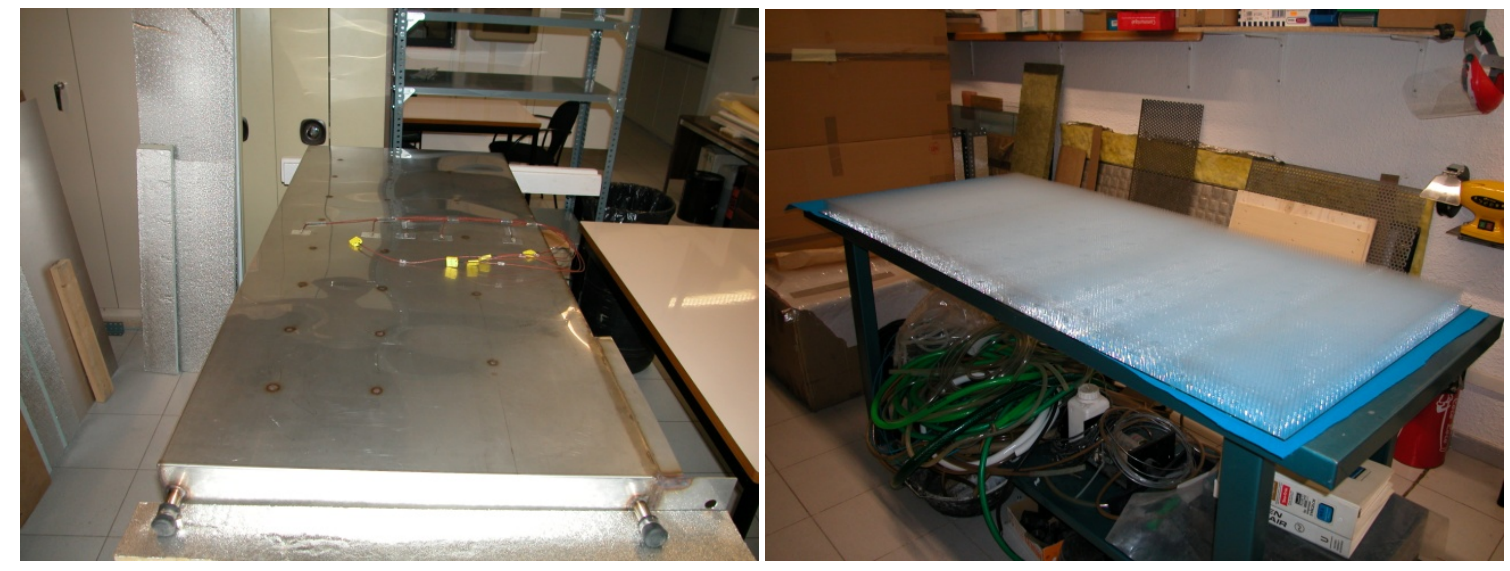

Figure 3: parallelepiped storage element (left), transparent insulation material (right)

Pictures corresponding to the assembly of the collector-storage element are shown in Figure 3. On the left, the parallelepiped storage tank with some thermocouple sensors can be observed. On the right, the transparent insulation material glued on the single-pane glass skin can be seen. 
In Figure 4, the appearance of the multi-functional façade element can be visualized from both sides. In the indoor view, the resistive thermal device (RTD) with radiation shield, and in the outdoor view, the pyranometers measuring the total and diffuse radiation on the façade surface can be noticed.

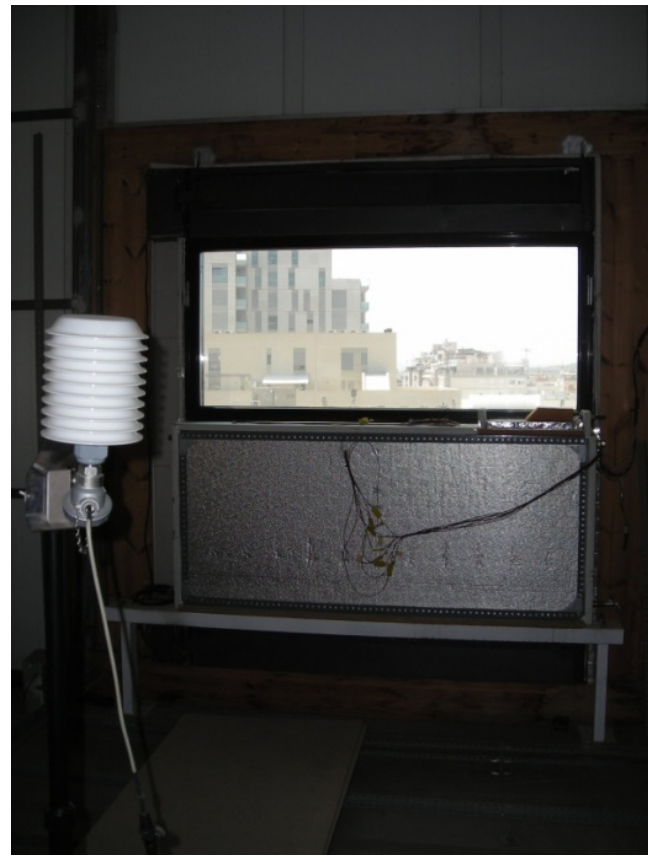

(a)

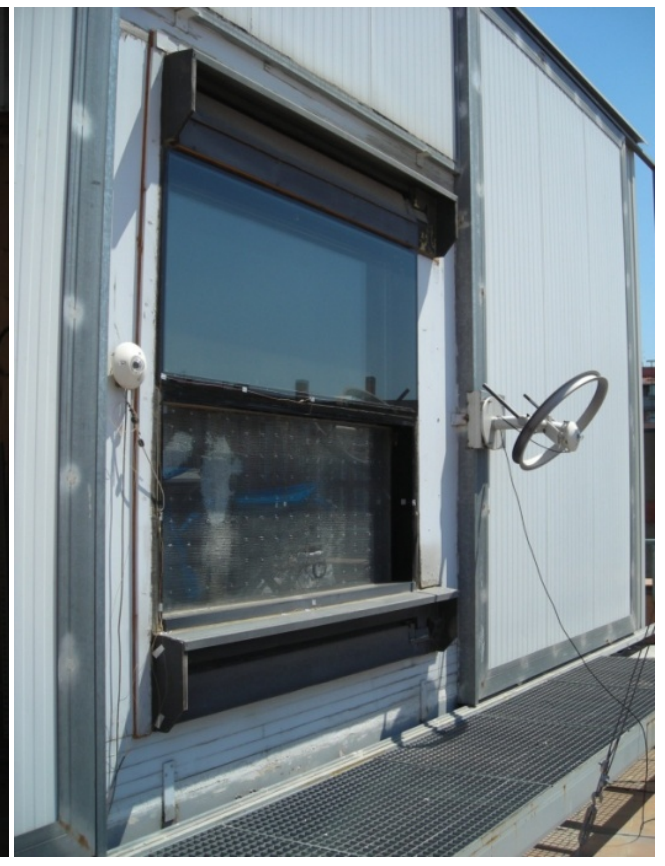

(b)

Fig. 4: indoor (a) and outdoor (b) view of the multi-functional façade element

In order to study the CASE A, the ventilation channel is eliminated temporarily by removing the lower portion of the outer skin (see Figure 4.b). The upper portion of the ventilation channel adjacent to the inner double glazing is blocked as well.

The administration of the data acquisition unit is carried out by means of a data acquisition program developed in the CTTC.

\section{Numerical Model}

This work is based on the existing numerical platform (Damle et al., 2011) for the prediction of the thermal performance of buildings and solar systems. The buildings or solar systems are modeled as a collection of basic elements which can individually be solved for given boundary conditions. For each element, different levels of modeling can be employed, like one-dimensional or two-dimensional models, simplified energy balances or CFD models. The numerical platform permits linking different elements to form a specific configuration.

The global resolution algorithm of the numerical model is shown in Figure 5. At each iteration, inputs (e.g. pressure, temperature, etc.) are obtained from the neighbors, governing equations for each element are solved and the final outputs are supplied to the neighbor elements as boundary conditions. Iterations continue until convergence is reached at a given time step and next time step calculation starts as the variables are updated. Details of the numerical platform are explained in (Damle et al., 2011).

The main advantage of a modular object-oriented tool is the possibility of creating new elements/objects to model an innovative product while the rest of the elements to form a given configuration can remain unchanged. To model the present system, some existing objects with their respective numerical models are employed (e.g. OUTDOOR, COMPOSITE WALL, WALL, ROOM etc.) and two new objects are created, namely the Glazed Areas and Transparent Insulation (TI) Layer and the Parallelepiped Storage Element. The scheme of the system under study is shown in Figure 6. 


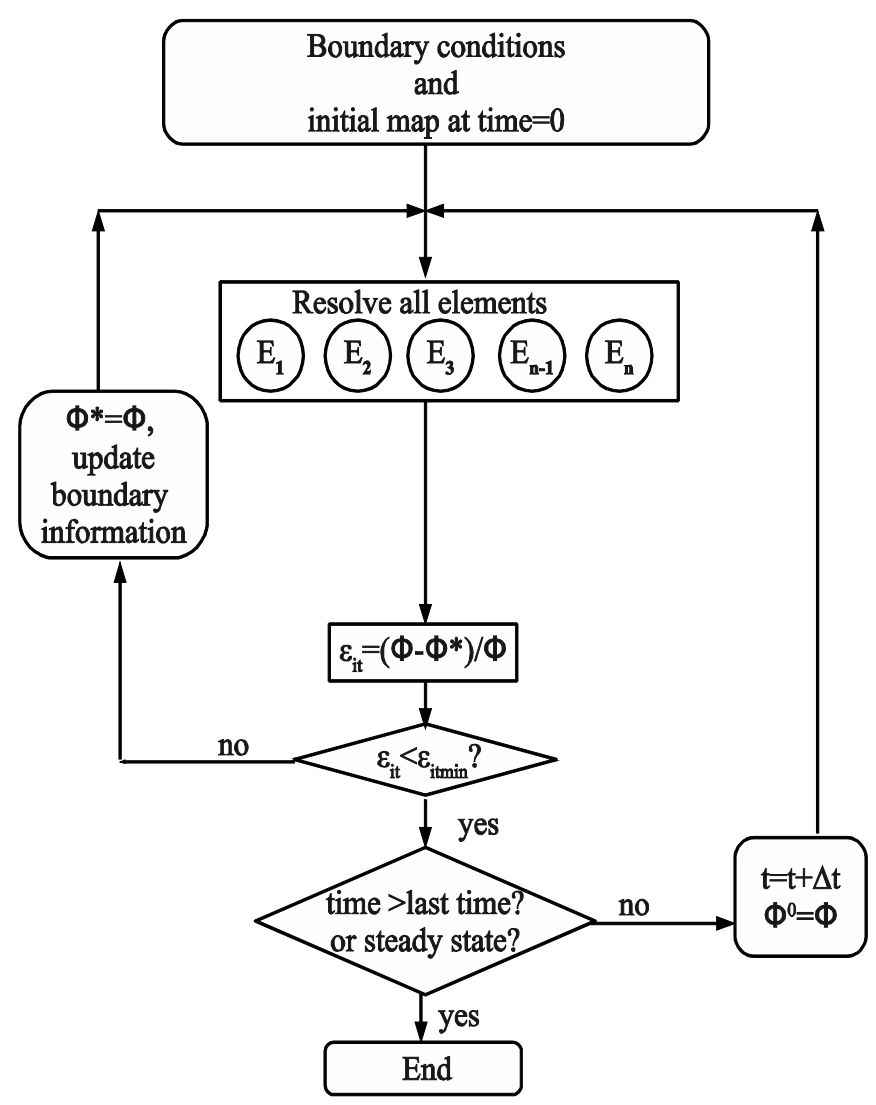

Fig. 5: Global resolution algorithm

As shown in Figure 6, an existing object is linked with two new objects to model the integrated storage element. The mathematical descriptions of the implemented objects are given below.

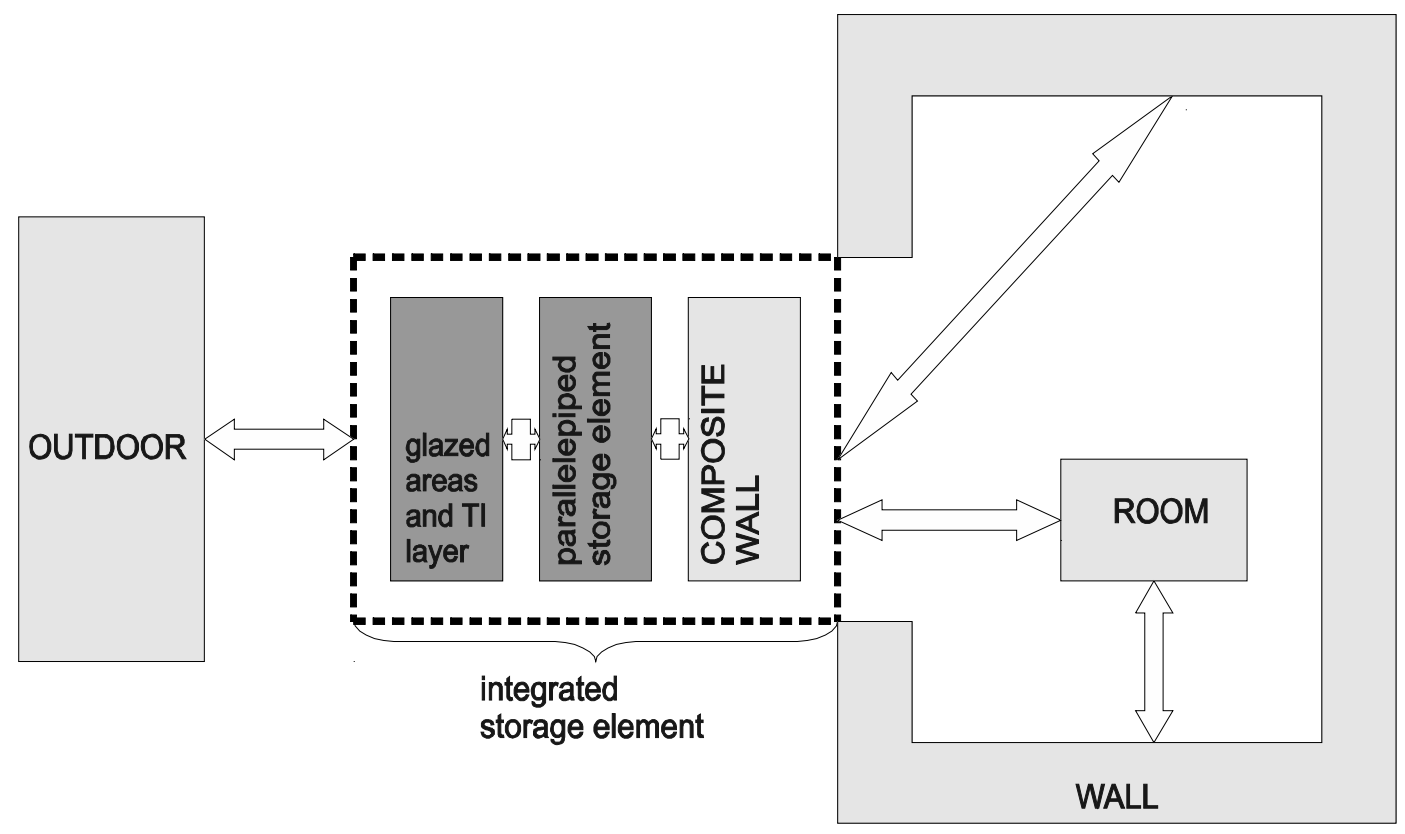

Fig 6: Scheme of the system as a collection of elements. Elements with uppercase letters represent existing elements. 


\subsection{Glazed Areas and TI Layer}

In the resolution of transparent walls, one-dimensional energy conservation equation with an additional source term to include solar absorption is considered.

Governing equations for the phenomena taking place in TI layer are the so-called Radiative Transfer Equation (RTE) whose solution provides the field of Intensity, $I$, for all the domain and the directions, and the Energy Equation (EE) whose solution provides the field of temperatures.

The change in the intensity in the direction $\mathrm{s}$ is found by summing the contributions from emission, absorption, scattering, and in-scattering in the following form, neglecting the time dependence of the intensity (Modest, 1993):

$\frac{d I}{d s}=\kappa_{\eta} I_{b \eta}-\beta_{\eta} I_{\eta}+\frac{\sigma_{s \eta}}{4 \pi} \int_{4 \pi} I_{\eta}\left(s_{i}\right) \phi_{\eta}\left(s_{i}, s\right) d \Omega_{i}$

where $\kappa_{\eta}$ is the linear absorption coefficient, $\sigma_{s \eta}$ is the linear scattering coefficient, $\phi_{\eta}$ is the scattering phase function, and $\beta_{\eta}$ is the extinction coefficient defined as:

$\beta_{\eta}=\kappa_{\eta}+\sigma_{s \eta}$

If we write the above formulation in terms of non-dimensional optical coordinates,

$\tau_{\eta}=\int_{0}^{s}\left(\kappa_{\eta}+\sigma_{s \eta}\right) d s=\int_{0}^{s} \beta_{\eta} d s$

and the single scattering albedo, defined as:

$\omega_{\eta}=\frac{\sigma_{s \eta}}{\kappa_{\eta}+\sigma_{s \eta}}=\frac{\sigma_{s \eta}}{\beta_{\eta}}$

leading to

$\frac{d I_{\eta}}{d \tau_{\eta}}=-I_{\eta}+\left(1-\omega_{\eta}\right) I_{b \eta}+\frac{\omega_{\eta}}{4 \pi} \int_{4 \pi} I_{\eta}\left(s_{i}\right) \phi_{\eta}\left(s_{i}, s\right) d \Omega_{i}$

Once eq. 5 is solved, field of intensity for all domain and all directions is obtained. RTE is coupled with EE which is of the following form:

$\rho c_{p} \frac{D T}{d t}=\nabla \cdot(k \nabla T)-\nabla \cdot\left(\vec{q}_{r}\right)$

where

$\nabla \cdot\left(\vec{q}_{r}\right)=\kappa_{\eta}\left(4 \pi I_{b}-\int_{4 \pi} I d \Omega\right)$

Eq. 7 is valid on spectral basis (for each wavelength) and states that the net radiation heat flux is equal to the emitted energy minus the absorbed irradiation. There is no scattering contribution in the radiation heat flux since scattering does not affect the energy content of any given unit volume.

The method of discrete ordinates ( $S_{N}$-Approximation) (Modest, 1993) is used to discretize RTE. A onedimensional model (intensity changing in the width direction of the TI material) assuming azimuth symmetry is adopted.

By means of the replacement of integrals over direction by numerical quadratures, like:

$\int_{4 \pi} f(s) d s=\sum_{i=1}^{n} \omega_{i} f\left(s_{i}\right)$

where the $\omega_{i}$ are the quadrature weights associated with the directions $s_{i}$. Thus the eq. 5 can be approximated by a set of $n$ equations: 


$$
\begin{array}{r}
\frac{d I\left(r, s_{i}\right)}{d s_{i}}=\kappa(r) I_{b}(r)-\beta(r) I\left(r, s_{i}\right)+\frac{\sigma_{s}(r)}{4 \pi} \sum_{j=1}^{n} \omega_{j} I\left(r, s_{j}\right) \Phi\left(r, s_{i}, s_{j}\right) \\
i=1,2, \ldots, n
\end{array}
$$

For symmetry, $\mathrm{n} / 2$ equations are in positive and $\mathrm{n} / 2$ equations are in negative directions.

The intensity is considered not to vary within a cone of azimuthal $\theta$ around the axe of the width which is perpendicular to the vertical confining planes.

A discretization has been carried out in a one-dimensional control volume, where the temperatures and the radiative properties are determined at the discretization nodes, as shown in Figure 7.

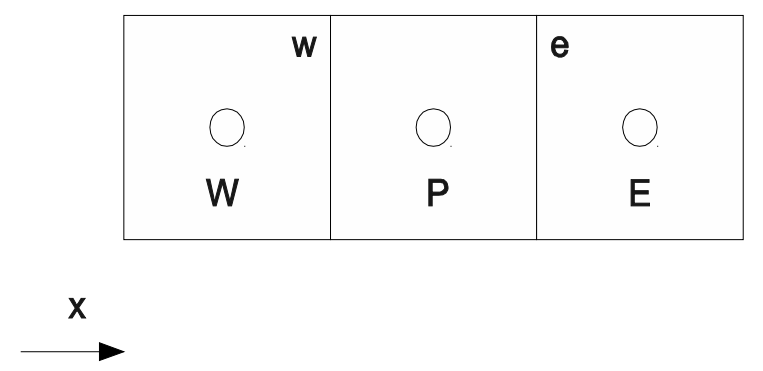

Fig. 7: Collocated mesh for RTE

Depending on the order of approximation $(\mathrm{N}=2,4,6,8)$ eq. 9 can be expressed in a discrete way using the respective ordinates and weights. Finally $\mathrm{n}$ equations are solved to obtain the radiative intensities at the nodes (see Modest, 1993 for details). From eq. 7 radiation heat flux is evaluated. Discrete form of eq. 6 is solved for the temperature field, resulting in an iterative procedure.

Heat fluxes considering thermal radiation, solar radiation, and natural convection from the neighboring elements (Outdoor and Parallelepiped Storage Element) constitute the boundary conditions of this element.

\subsection{Parallelepiped Storage Element}

The well-known multinode model proposed by Kleinbach et al. (1993) has been adapted to simulate the storage element integrated in the façade. The model considers that the tank is divided into $\mathrm{N}$ totally mixed levels of temperature. In addition, the heat conduction between each of these segments is also considered.

Reviewing multinode mathematical formulation, for each i-th tank node, energy balance can be written as follows:

$\rho c_{p} V \frac{d T_{i}}{d t}=h_{w} A_{i, w}\left(T_{\text {wall }, w}-T_{i}\right)+h_{e} A_{i, e}\left(T_{\text {wall }, e}-T_{i}\right)+k \frac{d T_{i}}{d y} S$

where $\rho, c_{p}, k$, and $\mathrm{V}$ are the density, specific heat capacity, conductivity, and volume of the fluid in segment $\mathrm{i}, h$ is the convection heat transfer coefficient in the storage element, $A$ and $\mathrm{S}$ are the lateral and cross sectional area of the tank, $T_{\text {wall }}$ is the temperature at the storage element inner wall, and $T_{i}$ is the temperature of the fluid at segment $i$. Subscripts $w$ and $e$ correspond to west and east confining walls of the storage element.

The use of adequate empirical information regarding the convection heat transfer coefficient within the storage element is essential in performance prediction of these systems (Rodriguez et al., 2009). Suggested values in a recent CFD work for this geometry are employed (Kizildag et al., 2011) to model the convection heat transfer within the storage element.

Dirichlet boundary conditions at the west and east confining vertical walls are adopted to solve the equations. These wall temperatures are calculated by means of a global energy balance considering the neighbor elements. 


\section{Experimental Validation of the Model}

The functioning of the implemented models has been tested by means of comparison with the experimental results. In this work only results corresponding to CASE A will be discussed. Mentioned experimental facility is used to register the meteorological data together with the relevant data corresponding to different zones of the integrated collector storage element. Part of the obtained data is used by the numerical model as boundary conditions.

To carry out the experimental validation, the data collected between the $31^{\text {st }}$ March and $3^{\text {rd }}$ Abril has been used. In Table 1 the measured data is given. The locations of the probes can be checked in Figures 2 and 4.

Tab. 1: Measured data

\begin{tabular}{|l|l|}
\hline A01 & Indoor wall temperature \\
\hline A02, A05, A06, A07, A08 & $\begin{array}{l}\text { Temperatures at the east confining wall of the } \\
\text { collector-storage element. }\end{array}$ \\
\hline A03 & Absorber temperature \\
\hline A04 & Outdoor wall temperature \\
\hline $01 I$ & Total radiation on horizontal surface \\
\hline $01 I_{d}$ & Diffuse radiation on horizontal surface \\
\hline $01 I_{t}$ & Total radiation on façade surface \\
\hline $01 W_{v}$ & Wind velocity \\
\hline $01 W_{d}$ & Wind velocity direction \\
\hline $01 \mathrm{Rh}$ & Relative humidity \\
\hline $01 T_{\text {out }}$ & Outdoor temperature \\
\hline $01 T_{\text {in }}$ & Indoor temperature \\
\hline
\end{tabular}

As a preliminary study, three indicative temperature readings are compared with the numerically calculated values. Mentioned temperature evolution graphs are presented with respect to day of the year, as shown in Figure 7. In graph (a) the temperature at the indoor wall of the collector-storage element, and in graph (c) the temperature at the outdoor wall of the prototype can be observed. Both figures show an acceptable degree of agreement for the test period, however at the indoor wall the temperature is slightly overestimated by the numerical model. In graph (b) the temperature at the absorber plate is given. Although the numerical model can predict the temperature trend at this location, relatively greater discrepancies are observed. The numerical model underestimates the day-time peak temperature by about $1^{\circ} \mathrm{C}$ and this underestimating behavior continues till the night time peak value is reached. During the cooling of the prototype after the day-time peak value, the discrepancies of more than $2^{\circ} \mathrm{C}$ can be observed. Night-time peak values (minimum values). It is important to note that unlike the figures (a) and (c), in figure (b) a time shift between the experimental and numerical values is perceived. The different level of agreement during the day-time and night-time peak values in absorber temperature can be due to the model employed in glazed areas and TI layer.

Even though the results globally show a certain level of agreement, some discrepancies have been observed. Many factors can be considered to justify the discrepancies. Thermophysical and optical properties of the materials are obtained from the manufacturers, which can include some uncertainty. Moreover, some materials of the prototype may have degraded with time, thus giving rise to a change in the properties. Some assumptions regarding parameters like ground or indoor room reflectivities or view factors are not very precise as some recommended values are employed. The temperatures in the indoor (A01) and outdoor (A04) wall of the prototype are quite well predicted, which indicate that natural convection and thermal radiation phenomena are quite well approximated by the adopted empirical models, however the same is not 
true for the absorber temperature (A03). This fact can be due to the difficulty in estimating the natural convection heat transfer coefficient within the collector-storage element, since the simple model used cannot reproduce the complex phenomena taking place in the tank. The model is unable to account for the laminar, transitional, turbulent, and relaminarization zones which coexist within the tank. The used natural convection heat transfer coefficient is obtained from steady state or statistically steady state calculations, while the phenomena under consideration are of transient character.

As a future work, using the modularity of the existing numerical platform, a CFD object which can reproduce the advanced physical phenomena taking place in the tank, or the test room, can be employed.

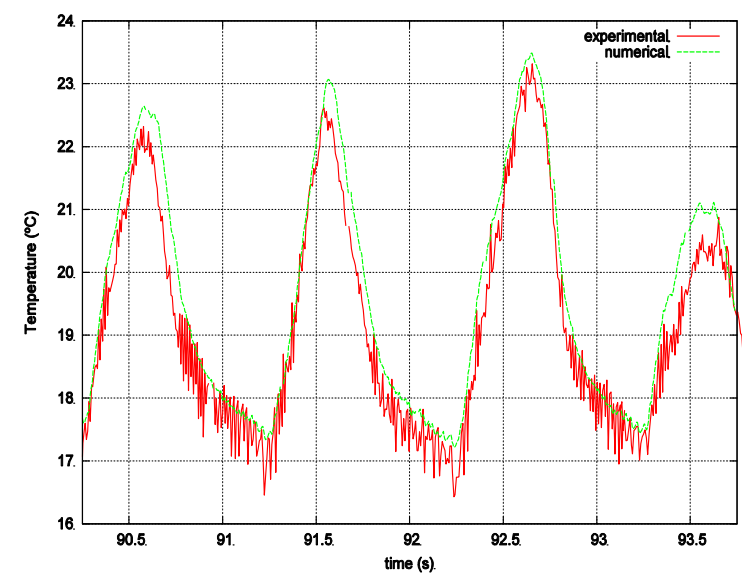

(a)

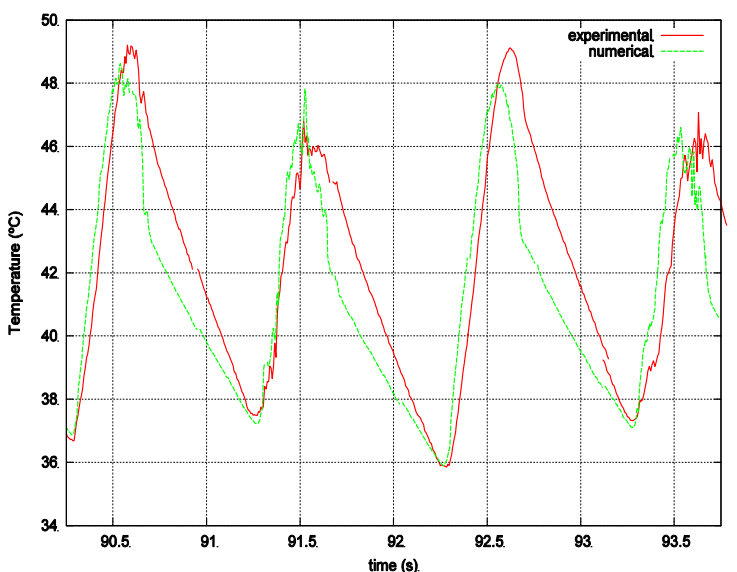

(b)

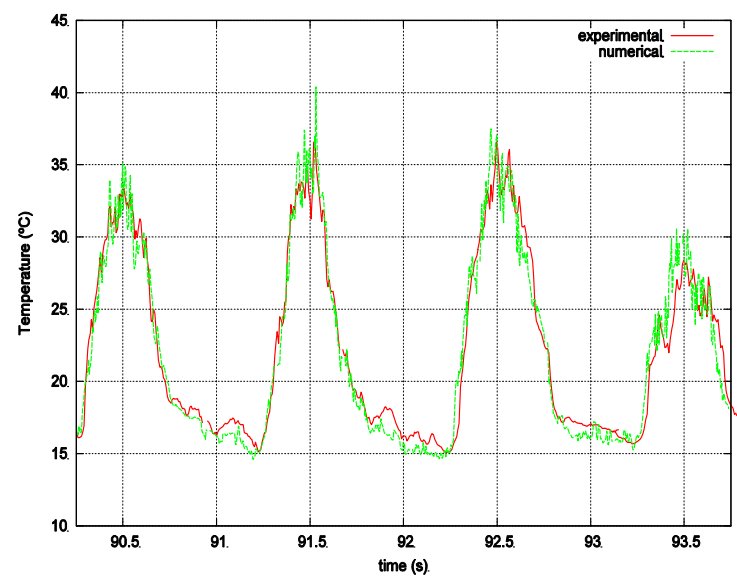

(c)

Fig. 7: Evolution of temperature at the (a) indoor wall (b) absorber plate (c) outdoor wall of the collector storage element

\section{Conclusion and Future Work}

A model to predict the thermal behavior of a multi-functional ventilated façade with a collector-storage element is implemented to an existing numerical platform. The comparison of the numerical and the experimental results indicates that the implemented model can be used to predict the thermal performance of the multi-functional façade with integrated storage element. The temperatures at the indoor and outdoor wall of the prototype are relatively well predicted while greater discrepancies are observed regarding the absorber plate temperature prediction. The well predicted values indicate that indoor and outdoor natural convection and thermal radiation phenomena are well approximated by the empirical model. The observed discrepancies can be due to various factors like the uncertainty in the termophysical and optical properties of the materials, 
errors regarding some assumed values like ground and room optical properties, view factors within the prototype layers, and errors associated with the collector-storage element heat transfer coefficient which is evaluated for a statistically steady state situation, while the numerical simulation under study is of transient character. More efforts have to be made to check and improve the models in glazed areas and TI layer. More numerical and experimental tests have to be carried out for different time periods to assure the higher quality of the simulations.

As future work, once more confidence is built with the preliminary CASE A results, a more detailed work will be carried out considering CASE B. In parallel, the indoor conditions will be controlled by means of the construction of an inner test cell which will act as a calorimeter.

\section{Acknowledgements}

This work has been partially funded by the "Ministerio de Ciencia e Innovación, Secretaría de Investigación”, Spain (ref. ENE-2009-09496).

\section{References}

1. Bloem, J.J., Baker, P.H., Strachan, P., Madsen, H., Vandaele, L., 2010. Dynamic Testing, Analysis and Modelling. http://www.dynastee.info

2. Damle, R., Lehmkuhl, O., Colomer, G., Rodriguez, I., 2011. Energy Simulation of Buildings with a Object-Oriented Tool. In Proceedings of the ISES Solar World Congress, Kassel, Germany.

3. Duffie, A., Beckman, W.A., 1991. Solar Engineering of Thermal Process. John Wiley and Sons Inc.

4. Faggembauu, D., Costa, M., Soria, M., Oliva, A., 2003. Numerical analysis of the thermal behaviour of ventilated glazed facades in Mediterranean climates. Part I: development and validation of a numerical model. Solar Energy, 75, pp 229-239.

5. Faggembauu, D., 2006. Heat transfer and fluid-dynamics in double and single skin façades. PhD Thesis. Universitat Politècnica de Catalunya (UPC), Terrassa.

6. Kizildag, D., Rodriguez, I., Oliva, A., 2011. On the validity of the Boussinesq approximation in a tall differentially heated cavity with water. In Proceedings of the $7^{\text {th }}$ International Conference on Computational Heat and Mass Transfer, Istanbul, Turkey.

7. Kleinbach, E.M., Beckman, W.A., Klein, S.A., 1993. Performance study of one-dimensional models for stratified thermal storage tanks. Solar Energy, Vol. 50, Issue 2, pp 155-166.

8. Modest, M.F., 1993. Radiative Heat Transfer. McGraw-Hill.

9. Pérez-Lombard, L., Ortiz, J., Pout, C., 2008. A review on buildings energy consumption information. Energy and Buildings, 40, pp. 394-398

10. Rodriguez, I., Castro, J., Perez-Segarra, C.D., Oliva, A., 2009. Unsteady numerical simulation of the cooling process of vertical storage tanks under laminar natural convection. International Journal of Thermal Sciences, Vol 48, Issue 4, pp 708-721. 